\title{
Photodynamic Therapy - A Non-invasive Treatment Modality for Precancerous Lesions
}

\author{
Kotya Naik Maloth ${ }^{*}$, Nagalaxmi Velpula², Srikanth Kodangal2, Mithare Sangmesh ${ }^{3}$, Kiran \\ Vellamchetla ${ }^{4}$, Sridevi Ugrappa ${ }^{5}$, Nagajyothi Meka ${ }^{6}$ \\ 'Department of Oral Medicine and Radiology, Mamata Dental College and Hospital, Khammam, Telangana, India \\ ${ }^{2}$ Department of Oral Medicine and Radiology, Sri Sai College Of Dental Surgery, Vikarabad, Telangana, India \\ ${ }^{3}$ Department of Oral Medicine and Radiology, HKDE Trust's Dental College and Hospital, Humnabad, India \\ ${ }^{4}$ Oral Medicine and Radiology, Clinical Practitioner, Kiran Dental Hospital, KPHB Colony, Hyderabad, Telangana, \\ India \\ ${ }^{5}$ Lecturer, Faculty Of Dentistry, Aimst Dental Institute, Aimst University, Semeling, 08100, Bedong, Malaysia \\ ${ }^{6}$ Department of Oral Medicine and Radiology, Dr. Hedgewar Smruti Runga Seva Mandals Dental College and \\ Hospital, Hingoli, Maharashtra, India
}

*Correspondence to Kotya Naik Maloth, MDS; Department of Oral Medicine \& Radiology, Mamata Dental College \& Hospital, Khammam, Telangana, India.

Tel: +91-9885617131;

Fax: 08742-255545;

Email:

dr.kotyanaik.maloth@gmail.com

Published online 7 January 2016

\begin{abstract}
Introduction: Oral premalignant lesions are conditions having high potential tendency for transformation into malignancy. The use of a conservative and effective treatment modality is one of the best strategies for cancer prevention. Photodynamic therapy (PDT) is a noninvasive method for topical and selective treatment of oral precancerous lesions. The present study was taken up to determine the efficacy of PDT in oral precancerous lesions.

Methods: The study consisted 13 patients with 24 oral leukoplakia (OL) lesions and 8 with 20 oral lichen planus (OLP) lesions, divided into control and study groups. These lesions were affecting various intraoral sites, the buccal mucosa being the most common site followed by tongue and gingiva. The treatment regimen of PDT included 98\% 5-aminolevulinic acid (5-ALA) which is topical applied and irradiated with light emitting diode (LED) of $420 \mathrm{~nm}$ wavelengths at several sessions.

Results: In OL $16.6 \%$ of cases showed complete response, $66.6 \%$ partial response and $16.6 \%$ no response of the lesions to the treatment. In OLP $80 \%$ and $20 \%$ of the lesions showed partial and no response respectively. The differences with control groups for OL + OLP were found to be significant $(P<0.001)$.

Conclusion: Based on the results of the present study, we can conclude that PDT appears to be a feasible alternative to conventional therapy for oral premalignant lesions.

Keywords: 5-Aminolevlinic acid; Photodynamic therapy; Oral leukoplakia
\end{abstract}

\section{Introduction}

Precancerous lesions consist of tissue changes which are more frequently found to undergo malignant modifications than normal tissue of the same type. World Health Organization (WHO) defined precancerous lesion as a "morphologically altered tissue in which cancer is more likely to occur than its apparently normal counterpart," whereas precancerous condition is defined as "a generalized state associated with a significantly increased risk of cancer." Precancerous lesions include oral leukoplakia (OL), oral erythroplakia, stomatitis nicotina, actinic keratosis and Bowen disease. Among them, OL has greater risk for malignant transformation than the others, ${ }^{1}$ with an annual rate of approximately $0.8 \%-1 \% .^{2}$ The assessment of degree of epithelial dysplasia is required to establish a proper treatment for OL. Non-surgical therapy for OL include retinoid, lycopene, carotenoids, and photodynamic therapy. ${ }^{3}$

The name "lichen planus" was provided by the British physician Erasmus Wilson, who first described the condition in 1869. Oral lichen planus (OLP), is a common chronic inflammatory mucocutaneous disease affecting middle aged women with a prevalence rate of $1 \%$ to $2 \%$ worldwide, ${ }^{4}$ but in India it varies from $0.1 \%$ to $1.5 \% .{ }^{5}$ The annual malignant transformation rate of OLP varies $0.04 \%$ and $1.74 \%{ }^{4}$

Photodynamic therapy (PDT) is an effective treatment modality of OLP, OL and initial stages of head and neck cancer. ${ }^{6}$ The synonyms of PDT are photoradiation therapy, phototherapy, or photochemotherapy, which uses a photosensitizer (photoactive dye), activated by light of a specific wavelength in the presence of oxygen. The activated photosensitizer transfers energy to the oxygen resulting in the formation of toxic oxygen species like singlet oxygen and free radicals, which are cytotoxic and vasculotoxic damaging proteins, lipids, nucleic acids, and other cellular components. Root of administration of photosensitizers may be injected intravenously, ingested 
orally, or applied topically depending on the type of agent. PDT is the treatment of choice for local diseased cells and tissue. ${ }^{6}$ So the present study was conducted to evaluate the efficacy of 5-aminolevlinic acid-mediated PDT (5-ALAPDT) as an alternative treatment modality for oral precancerous lesions.

\section{Methods}

This study was conducted to assess the efficacy photodynamic therapy using 5-ALA in OL and OLP patients. Following approval of the study by the ethics committee, informed consents were obtained from the study subjects. Histopathologically confirmed 13 patients presenting 24 OL lesions and 8 patients with 20 OLP lesions participated in this study. They were divided into two-groups.

1. Control group was treated with conventional therapy.

2. Study group was treated with photodynamic therapy.

Instruments and Materials Used for Photodynamic Therapy

1. 5-ALA - Photosensitizer

2. Light emitting diode (LED) light (blue light with a wavelength of $420 \mathrm{~nm}$ and intensity $>500 \mathrm{~mW} / \mathrm{cm}^{2}$ ) manufactured by Dentsply, model: QHL 75.

5-ALA: In the present study photosensitizer used was 5-aminolevlinic acid hydrochloride (Delta-ALA. HCL; 5-amino-4-oxo-pentanoic acid HCL; ALA) with a chemical formula of $\mathrm{C}_{5} \mathrm{H}_{9} \mathrm{NO}_{3} . \mathrm{HCL}$ and molecular weight of 167.59 AMU. This was purchased from SIGMAALDRICH (Icon Biosystems) of the United States. It consists of a yellowish white powder soluble in water, at a concentration of $49.00-51.00 \mathrm{mg} / \mathrm{ml}$. 5-ALA is a pro-drug; it serves as a precursor to photosensitizer, Protoporphyrin IX (PpIX), in heme biosynthesis. Topical ALA and its esters have been used for the treatment of pre-cancerous conditions, as well as for skin basal and squamous cell carcinoma. 5-ALA is a second generation photosensitizer, approved by FDA.

LED Light: In the present study we used LED blue light with a specific wavelength of $420 \mathrm{~nm}$ and intensity $>500$ $\mathrm{mW} / \mathrm{cm}^{2}$, providing intense uniform illumination.

Procedure: The lesions were cleaned with cotton-wool soaked in a soap-free cleansing lotion, before application of photosensitizer. 5-ALA was used as a photosensitizer. $50 \mathrm{mg}$ of 5-ALA powder was mixed with $1 \mathrm{ml}$ water, yielding a clear colourless solution. This solution applied topically on the lesions, except for a margin of 5-6 mm around them, 30 minutes prior to exposition with the LED at a wavelength of $420 \mathrm{~nm}$ (blue-light). Patients were instructed to sit for 30 minutes for the incubation period of 5-ALA. Then, lesions and the 5-6 mm surrounding area were illuminated with a spot size of $1 \mathrm{~cm}^{2}$ for $10 \mathrm{~min}-$ utes (with 3 minutes fractionization).

Clinical evaluation for Oral Lichen Planus

For OLP, the response rate was assessed clinically by two measures: (a) scoring symptoms and $(b)$ the rate of reduction in size of the lesions. The outcome of the treat- ment was by using symptom scores and size of the lesion from before (Figure 1A) and after [4 weeks] (Figure 1B) the treatment. The symptoms and size of the lesion before and after the treatment were assessed by using visual analogue scale (VAS) from 0 to 3 and scaled tongue blade respectively.

Clinical Evaluation for Oral Leukoplakia

Complete response (CR): Lack of visible lesion confirmed by clinical evaluation.

Partial response (PR): At least $20 \%$ reduction in size of the lesion.

No response (NR): Less than $20 \%$ reduction in size of the lesion.

At the end of the 4 week after completion of the PDT all OL lesion responses were evaluated (Figure 2A-2C).

\section{Results}

In PDT the standard mean age among study subjects in oral leukoplakia was $39.17 \pm 14.75$ and in oral lichen planus $33.60 \pm 9.28$, whereas in conventional therapy the standard mean age in oral leukoplakia was $39.73 \pm 13.18$ and in oral lichen planus $38.00 \pm 7.53$. According to the distribution of OL and OLP lesions (Table 1) for PDT, in OL, 9 (75.0\%) lesions were on the buccal mucosa, 2 $(16.66 \%)$ were on the tongue and $1(8.33 \%)$ lesion on the attached gingiva, and in OLP, 9 (90.0\%) lesions were on the buccal mucosa, 1 (10.0\%) lesion on the attached gin-
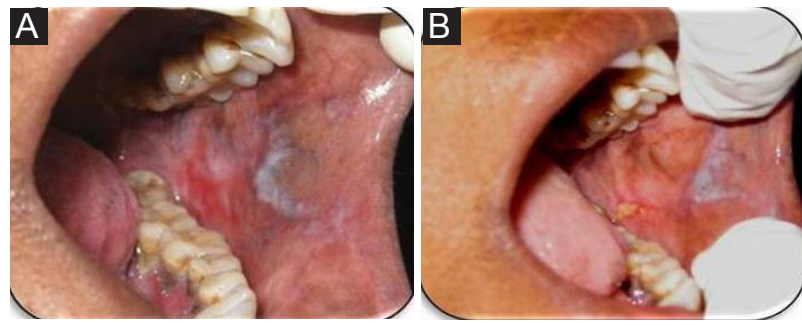

Figure 1. (A) Oral Lichen Planus (OLP) Lesion Before Therapy; (B) OLP Lesion After Therapy.
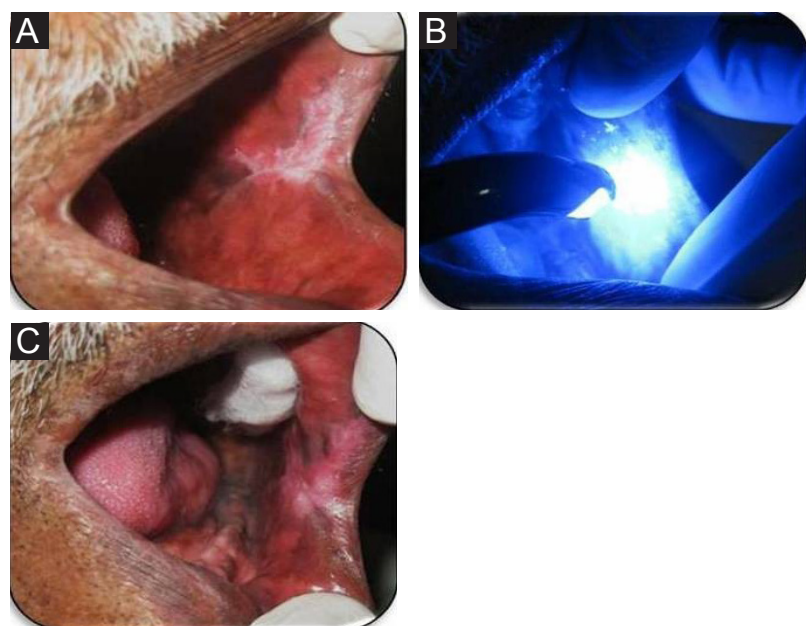

Figure 2. (A) Oral Leukoplakia (OL) Lesion Before Therapy; (B) OL Lesion During Therapy; (C) OL Lesion After Therapy. 
giva. Whereas in conventional therapy in OL, 10 (83.33\%) lesions were on the buccal mucosa, 1 (8.33\%) was on the tongue and $1(8.33 \%)$ lesion on attached gingiva, in OLP, 6 $(60.0 \%)$ lesions were on buccal mucosa, $2(20.0 \%)$ on the attached gingiva and $2(20.0 \%)$ on the tongue.

In OL study subjects, with PDT, from the 12 lesions found, 2 (16.66\%) completely responded, 8 (66.66\%) showed partial response and $2(16.66 \%)$ showed no response. Whereas, with conventional therapy, of the 12 lesions found, 2 (16.66\%) showed partial response and $9(75.0 \%)$ showed no response. The majority of patients had no response in the conventional therapy while in the PDT group, the majority obtained partial response and the difference was statistically significant. Data was assessed using the paired $t$ test. ( $P=0.007$; Table 2; Figure 3 ).

In OLP study subjects, with PDT, of the 10 lesions found, 8 (80.0\%) were with partial response and $2(20.0 \%)$ showed no response, whereas, in conventional therapy, 10 lesions were found of which, $8(80.0 \%)$ were with partial response and $2(20.0 \%)$ showed no response. (Table 3 ).

The lesion size scores were recorded before and after ther-

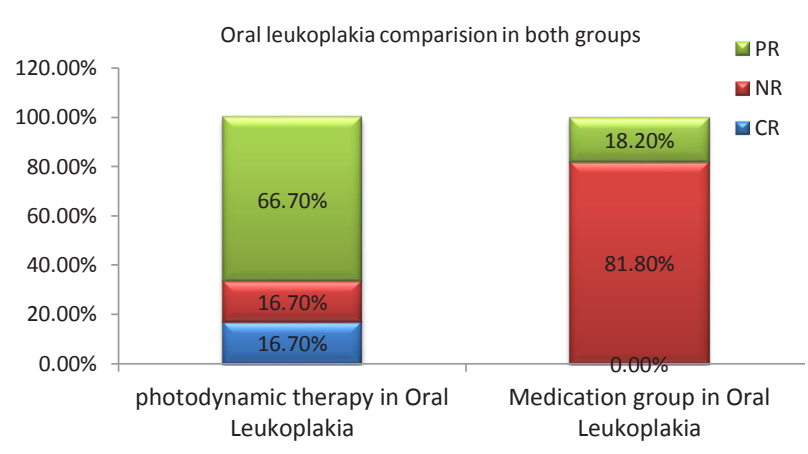

Figure 3. Comparison of Both the Groups in Lukoplakia. apy for OL patients. Twelve lesions had a mean size score of $1.82 \pm 0.89$ before therapy and $1.16 \pm 0.98$ after therapy. The mean reduction in size score was 0.66 according to paired $t$ test and this difference was highly significant statically $(P<0.001)$.

Lesion size scores were recorded before and after therapy for OLP patients, 10 lesions had a mean size score of $2.22 \pm 0.79$ before, and $1.41 \pm 0.74$ after therapy. The mean reduction in size score was 0.81 according to the paired $t$ test. This difference was statistically highly significant. $(P<0.001$; Table 4$)$.

The symptomatic (VAS) scores were recorded before and after therapy for OLP patients. Before therapy, of the 20 lesions, 13 had a score of 3 (severe burning sensation) and 7 had a score of 2 (moderate burning sensation). All the lesions showed an improvement after therapy as 4 lesions had a score of 1 (mild burning sensation), and 16 had a score of 0 (no burning sensation) which was significant based on the assessment by Wilcoxon signed ranks test $(P=0.004$; Table 5)

\section{Discussion}

Oral cancer considered worldwide as the fifth most common cancer. The early detection and treatment of oral cancerous lesions is prime important as it has low 5-years survival rate in advanced stages. Identification and elimination of earliest precancerous stages is one of the best strategies to prevent their further transformation into malignancy. ${ }^{7}$ The survival rate of oral cancer patients remains low although various treatment modalities have been used like radical surgical excision, chemotherapy and radiation therapy, separately or in combination.

Apart from being preceded by precancerous lesions oral cancers can arise clinically in normal oral mucosa, with

Table 1. Location of the Lesion

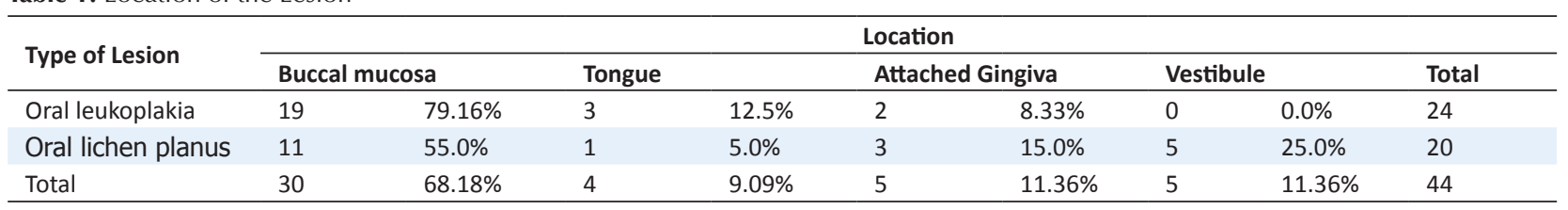

Table 2. Comparison of Both the Groups in Oral Leukoplakia.

\begin{tabular}{|c|c|c|c|c|}
\hline \multirow[t]{2}{*}{ Oral Leukoplakia } & \multicolumn{2}{|c|}{ Photodynamic Therapy in Oral Leukoplakia } & \multicolumn{2}{|c|}{ Medication Group in Oral Leukoplakia } \\
\hline & No. & $\%$ & No. & $\%$ \\
\hline \multicolumn{5}{|l|}{ Response } \\
\hline CR & 2 & $16.7 \%$ & 0 & $0.0 \%$ \\
\hline NR & 2 & $16.7 \%$ & 9 & $81.8 \%$ \\
\hline PR & 8 & $66.7 \%$ & 2 & $18.2 \%$ \\
\hline
\end{tabular}

$\mathrm{P}=0.007$; significant

Table 3. Comparison of Both the Groups in OLP.

\begin{tabular}{|c|c|c|c|c|}
\hline \multirow[t]{2}{*}{ Oral Lichen Planus } & \multicolumn{2}{|c|}{ Photodynamic Therapy in Oral Lichen Planus } & \multicolumn{2}{|c|}{ Medication Group in Oral Lichen Planus } \\
\hline & No. & $\%$ & No. & $\%$ \\
\hline \multicolumn{5}{|l|}{ Response } \\
\hline CR & 0 & $0.0 \%$ & 0 & $0.0 \%$ \\
\hline NR & 2 & $20.0 \%$ & 2 & $20.0 \%$ \\
\hline PR & 8 & $80.0 \%$ & 8 & $80.0 \%$ \\
\hline
\end{tabular}


Table 4. Comparison of Size of the Lesion in Both the Groups Before and After Therapy

\begin{tabular}{|c|c|c|c|c|c|}
\hline & \multicolumn{2}{|c|}{ Before Treatment } & \multicolumn{2}{|c|}{ After Treatment } & \multirow{2}{*}{$P$ Value } \\
\hline & Mean & SD & Mean & SD & \\
\hline Photodynamic therapy in oral leukoplakia & 1.82 & 0.89 & 1.16 & 0.98 & $<0.001$ \\
\hline Photodynamic therapy in oral lichen planus & 2.22 & 0.79 & 1.41 & 0.74 & $<0.001$ \\
\hline Medication group in oral leukoplakia & 2.09 & 0.77 & 1.93 & 0.75 & 0.017 \\
\hline Medication group in oral lichen planus & 2.27 & 0.88 & 1.74 & 0.77 & 0.001 \\
\hline
\end{tabular}

Paired $t$ test.

Table 5. Symptom (VAS) Score - OLP

\begin{tabular}{|c|c|c|c|c|c|c|c|c|c|}
\hline & \multicolumn{4}{|c|}{ Pre-treatment } & \multicolumn{4}{|c|}{ Post-treatment } & \multirow{3}{*}{$P$ Value } \\
\hline & \multicolumn{2}{|c|}{2} & \multicolumn{2}{|c|}{3} & \multicolumn{2}{|c|}{0} & \multicolumn{2}{|c|}{1} & \\
\hline & No. & $\%$ & No. & $\%$ & No. & $\%$ & No. & $\%$ & \\
\hline Photodynamic therapy in oral lichen planus & 3 & $42.9 \%$ & 7 & $53.8 \%$ & 8 & $50.0 \%$ & 2 & $50.0 \%$ & 0.004 \\
\hline Medication group in oral lichen planus & 4 & $57.1 \%$ & 6 & $46.2 \%$ & 8 & $50.0 \%$ & 2 & $50.0 \%$ & 0.004 \\
\hline
\end{tabular}

a prevalence of $4.6 \%$ in general population. ${ }^{8}$ The annual rate of malignant transformation in oral epithelial dysplasia, leukoplakia with severe dysplasia and in OLP quoted as $14 \%, 43 \%$ and $0.2 \%$ respectively. ${ }^{9}$

$\mathrm{OL}$ is a common premalignant lesion having a high potential for malignant transformation. Current management includes elimination of risk factors such as smoking, along with active therapy such as topical cytotoxic therapy, systemic retinoid therapy, surgical excision, cryosurgery or laser therapy, but none are entirely satisfactory or universally effective. ${ }^{10}$ Recent studies have demonstrated that topical 5-ALA mediated PDT is an effective alternative treatment modality for OL.?

Among many treatment modalities available for OLP, high potency topical steroids remain the most effective and reliable modality. In a study conducted by Aghahosseini et al, a new procedure's such as methylene blue-mediated photodynamic therapy (MB-PDT), used in the treatment of OLP. ${ }^{11}$ But in present study we tried to determine the efficacy of 5-ALA mediated PDT for OLP.

Based on the various studies, presently PDT can be considered as an alternative treatment modality for OL and OLP. ${ }^{12}$

PDT is a promising medical treatment and new approach in the field of cancer treatment. It utilizes photoactive dye (photosensitizer) in the presence of oxygen, which is activated by light, resulting localized photo damage and cell death by formation of oxygen species, such as singlet oxygen and free radicals. ${ }^{6}$

The early 1900 has led to the discovery of PDT by a German medical student, Oscar Raab. The term "photodynamic" was coined by Von Tappeneir to denote oxygen consuming chemical reactions in vivo. The first study on humans was performed by German physician Friedrich Meyer-Betz with porphyrins on his own skin in 1913 and named it photoradiation therapy (PRT). ${ }^{13}$ In 1982 Hayata et al used fibroptic lasers for exposures in PDT first time for treating early bronchial cancer. ${ }^{14}$ PDT also has antimicrobial properties and named as photodynamic antimicrobial chemotherapy (PACT) such as antibacterial, antifungal, and antiviral properties and used alternative to drug resistant organisms. ${ }^{6}$

In recent times of dentistry the application of PDT is rapidly growing in the management of oral cancers, bacterial, viral and fungal infections and for diagnostic purpose (photodynamic diagnosis [PDD]) of oral lesions undergoing malignant transformation. PDT also has few non-oncological applications for the treatment of actinic keratosis, rheumatoid arthritis, psoriasis and age-related macular degenerations. ${ }^{6}$

PDT involves 3-components ${ }^{6}$ (1). Light source, (2) Photosensitizing agents (Photosensitizers), and (3) Tissue oxygen (Figure 4).

Mechanism of Photodynamic therapy

PDT mediates tumor destruction by three possible mechanisms in vivo which includes cellular, vascular, and immunological mechanisms (Figure 5). ${ }^{6}$

Firstly, the destruction of tumor cells by reactive oxygen species (ROS) (Cellular effects). Secondly, vascular destruction of the tumor leading to thrombus formation followed by infarction of the tumor (Vascular effects). Thirdly, activation of an immune response against tumor cells (Immunological effects).

In our study, 7 patients with 12 oral leukoplakia lesions and 4 patients with 10 oral lichen planus lesions were treated with topically applied 98\% 5-ALA as a photosensitizer and LED at a wave-length of $420 \mathrm{~nm}$ (blue light). ALA applied 30 minutes prior to illumination and treatment procedure carried for 12 minutes (with 3 minutes fractionization). In previous studies, McGillis and Fein ${ }^{15}$

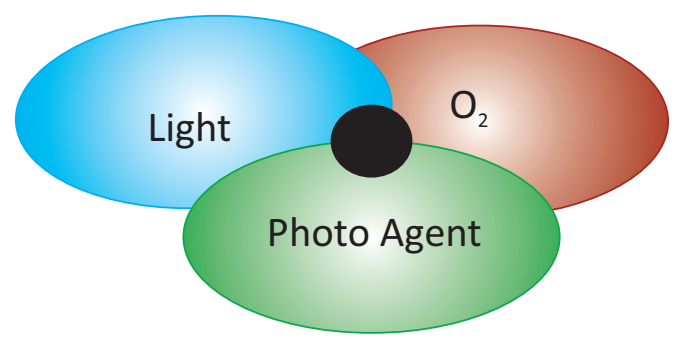

Figure 4. PDT Comprises of 3-Componenets. 


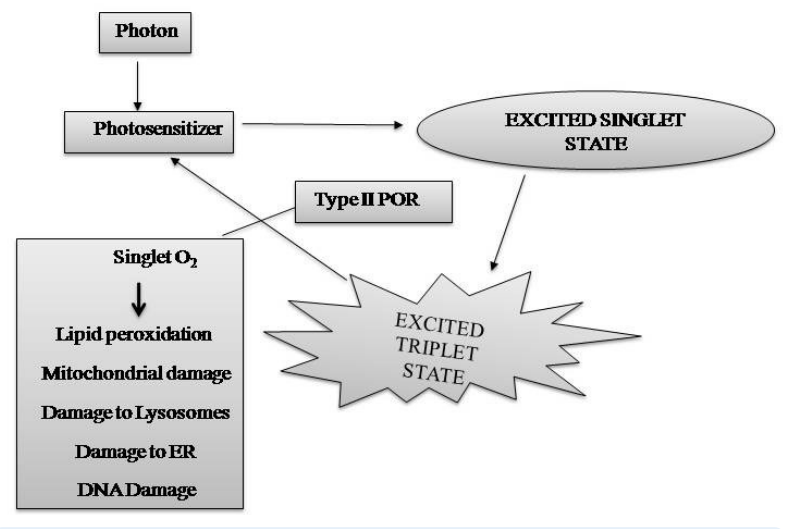

Figure 5. Mechanism of PDT Within Cell.

and Rivard and $\mathrm{Ozog}^{16}$ have also applied ALA for 30 minutes before illumination and exposition to light for 10 minutes in 3 fractions.

In most of the previous studies the light sources used were lasers at $635 \mathrm{~nm}$, Kübler et al, ${ }^{17}$ Fan et al, ${ }^{18}$ Kubler et al, ${ }^{19}$ Sieron et al, ${ }^{20}$ Sieroń et $\mathrm{al},{ }^{21} \mathrm{Tsai}$ et $\mathrm{al},{ }^{22}$ Chen et al, ${ }^{23}$ Lin et $\mathrm{al},{ }^{24}$ and $585 \mathrm{~nm}$, Franco, ${ }^{25}$ Shafirstein et al. ${ }^{26}$ But, because of their bulkiness and high cost, we have chosen LED at $420 \mathrm{~nm}$, like McGillis and Fein, ${ }^{15}$ Rivard and Ozog, ${ }^{16}$ Ericson et $\mathrm{al}_{,}{ }^{27}$ Jerjes et $\mathrm{al},{ }^{28}$ as it is cheaper, convenient, safe and easy to use in the treatment of OL and OLP.

In the present study, $12 \mathrm{OL}$ lesions were treated with 5-ALA mediated PDT, among which 2 (16.7\%) showed complete response, $8(66.67 \%)$ partial response and 2 (16.7\%) no response. The mean size score for 12 leukoplakia lesions before therapy was $1.82 \pm 0.89$ and $1.16 \pm 0.98$ after therapy, this difference was significant statistically $(P<0.001)$.

The present study results obtained correlated with the study conducted by Kubler et al, ${ }^{17}$ Kubler et al, ${ }^{19}$ Tsai et $\mathrm{al}^{22}$ and Chen et $\mathrm{al},{ }^{29}$ where in the study conducted by Kubler et al, ${ }^{17} 6$ leukoplakia cases were treated by topical application of 5-ALA (20\% cream) and irradiated with argon-pumped dye laser resulting complete response in 2 (33.33\%) patients, partial response in $3(50.0 \%)$ patients and no response in $1(16.66 \%)$ patient.

In the other hand, our results are inconsistent with the results of the study conducted by Fan et al, ${ }^{18}$ Kubler et al ${ }^{19}$ and Franco. ${ }^{25}$

The possible reasons could be the light source, where in the above studies the light used was laser, but we used LED, the mode of administration of 5-ALA in the above studies was oral administration whereas we have used topical application. Problem with oral administration is the long photosensitivity period and long duration follow up, while our follow up was only for a short duration.

In the present study, we have compared PDT with conventional treatment. In conventional treatment we have used preparation of retinoic acid and treated the lesions for a period of 4 weeks and obtained the following results: none of the patients showed complete response, $81.8 \%$ showed no response and only $18.2 \%$ showed partial response. The differences were statically significant $(P=0.007)$, when compared PDT with conventional treatment.

The light source used in our study (LED) could be one of the reasons the majority of the patients $(66.7 \%)$ were in partial response category, whereas most of the previous studies used lasers. The duration of light application in our study was for shorter periods and less number of sessions per week.

OLP: The use of 5-ALA as the photosensitizer for OLP lesions in our study was first of its kind, hence there was no literature review except Kirby et al in 1999 who reported one case of hypertrophic lichen planus on the penis treated by PDT using 5-ALA for about two times in a week. ${ }^{30}$ In the present study, it was observed that in OLP, there was a decrease in the mean size score of the lesions: before therapy it was $2.22 \pm 0.79$, after therapy it became $1.41 \pm$ 0.74 , and this difference was significant $(P<0.001)$.

In the present study, we evaluated burning sensation symptom in OLP lesions. In PDT study group, before treatment $42.9 \%$ had moderate burning sensation $(\mathrm{V}=2)$ and $53.8 \%$ had severe burning sensation $(\mathrm{V}=3)$. In the conventional treatment group $57.1 \%$ were in moderate burning sensation $(\mathrm{V}=2)$ and $46.2 \%$ were in the severe burning $(\mathrm{V}=3)$. After treatment, in the PDT group, 50.0\% of the sample showed mild burning sensation $(\mathrm{V}=1)$ and $50.0 \%$ of them were completely relieved from burning sensation. Also, in the conventional group, 50\% showed mild burning sensation and 50\% showed complete regression in burning sensation. Therefore, there was no significant difference in burning sensation in both treatment modalities in OLP subjects.

There were previous studies done on OLP, but in all of them methylene blue was used as a photosensitizer. Aghahosseini et $\mathrm{al}^{31}{ }^{31}$ treated 13 patients with 26 OLP lesions with MB-mediated PDT and results were evaluated a week after single session of PDT and at follow up sessions up to 12 weeks. The average reduction in size of lesions was $44.3 \%$ which was statistically significant. In another study conducted by Aghahosseini et al, ${ }^{11} 2$ patients with 5 OLP lesions were subjected to MB-mediated PDT and results were evaluated 2 weeks after a single session of PDT, resulting complete response in 2 lesions, and 2 other lesions showed partial response at 3-9 months follow up, and no response could be detected in one lesion.

In a study conducted by Sadaksharam et al, ${ }^{32} 20$ patients with symptomatic OLP were treated by using PDT with $5 \%$ methylene blue and irradiated with xenon arc lamp, at a wavelength $630 \pm 5 \mathrm{~nm}$, at a dose of $120 \mathrm{~J} / \mathrm{cm}^{2}$ per sitting in four sessions (1st, 4 th, 7 th and 15 th day). Patients were followed up at second and fourth week after the therapy which showed significant improvement in signs and symptoms of the lesion $(P<0.001)$.

The present study results showed that ALA-PDT has a significant beneficial effect in the control of the lesion and symptoms of OLP. PDT appears to be an alternative modality in the treatment of OLP, as results were no way less when compared to MB-mediated PDT. In the present study, we have compared PDT with conventional treatment, where we have used topical application of kenacort 
$0.05 \%$ in the conventional treatment and treated the lesions for 4 weeks. The results of conventional treatment were $20.0 \%$ showed no response and $80.0 \%$ showed partial response. These results were similar to the results of PDT study group of OLP.

Regarding OL, in our study, the comparison between PDT and conventional therapy showed statistically significant difference with $P=0.007$, whereas in OLP, both treatment modalities showed similar results.

The results of our study made us conclude that 5-ALA mediated PDT can be used as safe and effective treatment modality for OLP and OL. To evaluate the effectiveness of PDT further clinical trials have to be carried out on larger sample size with long-term follow ups.

\section{Conclusion}

OLP and OL are commonly encountered mucosal pathologies and are prone for higher malignant transformation $0.4 \%$ to $5 \%$ and $0.13 \%$ to $17.5 \%$, respectively. Though different treatment options are present, many studies have evaluated the efficacy of PDT (PDT is considered as the fourth modality, the first three being surgery, radiotherapy and chemotherapy, in the management of a different pathologies) as an alternative therapeutic modality. PDT has shown its potential outcome in the treatment of early stage oral cancer with excellent functional and cosmetic result with minimal side-effects. Though these studies had variable results, it has been documented that PDT can be used effective, non-invasive treatment modality for precancerous lesions like OL and OLP.

\section{Acknowledgements}

Authors acknowledge the immense help received from the scholar's Dr. C. Vani MDS.; Dr. Kesidi. Sunitha MDS.; Dr. C. K. Raju MDS.; Dr. Syed Afroz Ahmed MDS., Dr. Dr. Venkat Reddy MDS., Dr. Ch. Lalitha MDS., Dr. Stuti Goyal MDS., Dr. L. A. Swapna MDS., \& Dr. D. R. Sravan Kumar MDS, to bring the quality to this manuscript.

\section{Conflict of Interest}

None to be declared.

\section{References}

1. Reibel J. Prognosis of oral pre-malignant lesions: significance of clinical, histopathological, and molecular biological characteristics. Crit Rev Oral Biol Med. 2003;14(1):4762. doi:10.1177/154411130301400105.

2. Johann AC, Silveira-Junior JB, Souto GR, Horta MC, Aguiar MC, Mesquita RA. Metallothionein immune expression in oral leukoplakia. Med Oral Cir Buccal. 2008;13(3):E156160.

3. Ribeiro AS, Ribeiro SL. A review of the nonsurgical treatment of oral leukoplakia. Int J Dent. 2010;2010:186018. doi:10.1155/2010/186018.

4. Scott SD, Katharine NC. Lichen planus, lichenoid drug reactions, and Lichenoid mucositis. Dent Clin N Amr. 2005;49(1):77-89. doi:10.1016/j.cden.2004.08.004

5. Mehta FS, Hamner JE III. Tobacco- related oral mucosal lesions and conditions in India;a guide for dental stu- dents, dentists and physicians. Br J Oral Maxillofacial Surg. 1995;33(5):336. doi:10.1016/0266-4356(95)90070-5.

6. Konopka K, Goslinski T. Photodynamic therapy in dentistry. $J$ Dent Res. 2007;86(8):694-707. doi:10.1177/154405910708600803.

7. Chen HM, Yu CH, Tsai T, Hsu YC, Kuo RC, Chiang CP. Topical 5 - aminolevlinic acid mediated photodynamic therapy for oral verrucous hyperplasia, oral leukoplakia and oral erythroleukoplakia. Photodiagnosis Photodyn Ther. 2007;4:44-52. doi:10.1016/j.pdpdt.2006.11.003.

8. Axéll T. Occurrence of leukoplakia and some other oral white lesion among 20,333 adult Swedish people. Community Dent Oral Epidemiol. 1987;15:46-51.

9. Lumerman H, Freedman P, Kerpel S. Oral epithelial dysplasia and the development of invasive squamous cell carcinoma. Oral Surg Oral Med Oral Pathol Oral Radiol Endod. 1995;79(3):321-329.

10. Scully C. Oral precancer: preventive and medical approaches to management. Eur J Cancer B Oral Oncol. 1995;31B(1):16-26. doi:10.1016/0964-1955(94)00049-a.

11. Aghahosseini F, Arbabi-Kalati F, Fashtami LA, Fateh M, Djavid GE. Treatment of oral lichen planus with photodynamic therapy mediated methylene blue; a case report. Med Oral Pathol Oral Cir Buccal. 2006;11:E126-1299. doi:10.1002/lsm.20278.

12. Jurczyszyn K, Ziółkowski P, Gerber H, Osiecka BJ. Potentiality of photodynamic therapy in dentistry - literature review. Dent Med Probl. 2007;44(2):255-258.

13. Meyer-Betz F. Investigations on the biological (photodynamic) action of hematoporphyrin and other derivatives of the blood and bile pigments. Deutsch Arch Klin Med .1913;112:476-503.

14. Hayata Y, Kato H, Konaka C, Ono J, Takizawa N. Haematoporphyrin derivative and laser photoradiation in the treatment of lung cancer. Chest. 1982;81:269-277.

15. McGillis ST, Fein H. Topical treatment strategies for non-melanoma skin cancer and precursor lesions. Semin Cutan Med Surg. 2004;23:174-183. doi:10.1016/j. sder.2004.06.005.

16. Rivard J, Ozog D. Henry ford hospital dermatology experience with levulan kerastick and blue light photodynamic therapy. J Drugs Dermatol. 2006;5(6):556-561.

17. Kübler AC, Kaus M, Hofele C, Zoller J. Photodynamic therapy of oral leukoplakia by topical application of 5-aminolevulinic acid (ALA) (abstract). J Craniomaxillofac Surg. 1996;24(1 Suppl):141.

18. Fan KF, Hopper C, Speight PM, Buonaccorsi G, MacRobert AJ, Bown SG. Photodynamic therapy using 5-aminolevulinic acid for premalignant and malignant lesions of the oral cavity. Cancer. 1996;78:1374-1383.

19. Kubler A, Haase T, Rheinwald M, Barth T, Mühling J. Treatment of oral leukoplakia by topical application of 5-aminolevlinic acid. Int J Oral Maxillofac Surg. 1998;27:466-469. doi:10.1016/s0901-5027(98)80040-4.

20. Sieron A, Namyslowski G, Misiolek M, Adamek M, Kawczyk-Krupka A. Photodynamic therapy of premalignant lesion and local recurrence of laryngeal and hypopharyngeal cancers. Eur Arch Otorhinolaryngol. 2001;258:349-352. doi:10.1016/s0901-5027(98)80040-4.

21. Sieroń A, Adamek M, Kawczyk-Krupka A, Mazur S, Ilewicz L. Photodynamic therapy (PDT) using topically applied $\delta$-aminolevlinic acid (ALA) for the treatment of oral Leukoplakia. J Oral Pathol Med. 2003;32:330-336. 
doi:10.1034/j.1600-0714.2003.00068.x

22. Tsai JC, Chiang CP, Chen HM, et al. Photodynamic therapy of oral dysplasia with topical 5-aminolevulinic acid and light-emitting diode array. Lasers Surg Med. 2004;34:18-24. doi:10.1002/lsm.10250.

23. Chen HM, Chen CT, Yang H, et al. Successful treatment of oral verrucous hyperplasia with topical 5-aminolevulinic acid-mediated photodynamic therapy. Oral Oncol. 2004;40:630-637. doi:10.1016/j.oraloncology.2003.12.010.

24. Lin HP, Chen HM, Yu CH, Yang H, Wang YP, Chiang CP. Topical photodynamic therapy is very effective for verrucous hyperplasia and oral erythroleukoplakia. $J$ Oral Pathol Med. 2010;39:624-630. doi:10.1111/j.16000714.2010.00935.x.

25. Franco $\mathrm{R}$ Jr. Photodynamic treatment of laryngeal leukoplakia with ALA. Otolaryngol Head Neck Surg. 2006;135(2):197-8.

26. Shafirstein G, Bäumler W, Sigel E, Fan CY, Berry K. Utilizing 5-aminolevulinic acid and pulsed dye laser for photodynamic therapy of oral leukoplakia-pilot study. Head Neck Oncol. 2010;2(Suppl 1):O40. doi:10.1111/j.16000714.2010.00935.x.

27. Ericson MB, Wennberg AM, Larkö O. Review of photody- namic therapy in actinic keratosis and basal cell carcinoma. Ther Clin Risk Manag. 2008;4(1):1-9.

28. Jerjes W, Hamdoon Z, Hopper C. Photodynamic therapy in the management of potentially malignant and malignant oral disorders. Head Neck Oncol. 2012;4(16):1-7.

29. Chen HM, Yu CH, Tu PC, Yeh CY, Tsai T, Chiang CP. Successful treatment of oral verrucous hyperplasia and oral leukoplakia with topical 5-aminolevulinic acid-mediated photodynamic therapy. Lasers Surg Med. 2005;37:114-122. doi:10.1002/lsm.20214.

30. Kirby B, Whitehurst C, Moore JV, Yates VM. Treatment of lichen planus of the penis with photodynamic therapy. $\mathrm{Br} J$ Dermatol. 1999;141:765-766.

31. Aghahosseini F, Arbabi F, Fashtami LA, Esmaeeli G, Fateh M, Beitollahi JM. Methylene blue - mediated photodynamic therapy: a possible alternative treatment for oral lichen planus. Lasers Surg Med. 2006;38:33-38. doi:10.1002/ lsm.20278.

32. Sadaksharam J, Nayaki KP, Selvam NP. Treatment of oral lichen planus with methylene blue mediated photodynamic therapy--a clinical study. Photodermatol Pho€ toimmunol Photomed. 2012;28(2):97-101. doi:10.1111 /j.1600-0781.2012.00647 